\title{
Pengaruh Kualitas Pelayanan, Citra Perusahaan dan Kepuasan Pelanggan Terhadap Loyalitas Pelanggan Pada Perusahaan Daerah Air Minum di Kota Probolinggo
}

\author{
Tumini $^{1}$, M. Saiful Bahri ${ }^{2}$ dan Irvan Sumiafandi ${ }^{3}$ \\ Fakultas Ekonomi Universitas Panca Marga Probolinggo ${ }^{1,2,3}$
}

\begin{abstract}
This study aims to determine the effect of service quality, company image and customer satisfaction on customer loyalty in the local water company (PDAM) in Probolinggo. This study uses a quantitative approach with descriptive approaches and associative analysis. The method of data collection is by distributing questionnaires (questionnaires), observation, documentation and literature study. The data sources used are primary data in the form of a general description of the company and the results of distributing questionnaires and secondary data in the form of explanatory quotes of variables obtained from books on related variables. The sampling technique used is nonprobability sampling with the current number of customers as many as 20,000. The method of data analysis is multiple linear regression analysis using the help of SPSS 23 for Windows. The results showed that (1) simultaneously (together) service quality, company image and customer satisfaction had a significant effect on customer loyalty in the municipal water company (PDAM) of probolinggo, (2) partially (separately) service quality, image company and customer satisfaction have a significant effect on customer loyalty in the municipal water company (PDAM) of probolinggo, (3) the most dominant customer satisfaction variable affects the variable customer loyalty in the local water company (PDAM) in Probolinggo.
\end{abstract}

Keywords: Service Quality, Company Image, Customer Satisfaction, and Customer Loyalty.

\section{Pendahuluan}

Konsep penting dalam pemasaran tidak lepas dari Loyalitas pelanggan, khususnya dalam kondisi pasar dengan tingkat pertumbuhan yang rendah tapi persaingan ketat. (PDAM) kota Probolinggo menyadari bahwa kegiatan mempertahankan pelanggan lebih memberikan keuntungan dibandingkan jika perusahaan harus menarik pelanggan baru lagi. Melihat kondisi ini tidak heran apabila (PDAM) kota Probolinggo senantiasa berupaya untuk meningkatkan loyalitas pelanggannya guna menjaga kelangsungan dan kemajuan perusahaan. 
Loyalitas diartikan sebagai kesetiaan, yaitu kesetiaan terhadap suatu objek. Menurut Lovelock dan Wright dalam Haris (2016: 247) "Loyalitas menggambarkan kesediaan pelanggan dalam memakai barang atau jasa secara rutinitas dan eksklusif, dengan sukarela merekomendasikan kepada pengguna jasa air".

Faktor yang dapat mempengaruhi loyalitas pelanggan pada perusahaan jasa seperti (PDAM) kota Probolinggo khususnya yang harus diperhatikan, diantaranya yang paling utama adalah kepuasan dan layanan berpengaruh terhadap loyalitas pelanggan seperti citra perusahaan. Penelitian bertujuan untuk mengetahui pengaruh variabel $\mathrm{X} 1$, variabel $\mathrm{X} 2$, variabel $\mathrm{X} 3$ terhadap variabel $\mathrm{Y}$, maka peneliti bermaaksud untuk melakukan penelitian tentang "pengaruh variabel X1, variabel X2 dan variabel X3 terhadap Variabel Y pada obyek (PDAM) kota Probolinggo".

Dalam penelitian ini diambil rumusan masalah adalah: 1).Apakah ada pengaruh antara kualitas pelayanan, citra perusahaan, dan kepuasan pelanggan secara bersama-sama terhadap loyalitas pelanggan di (PDAM) kota Probolinggo? 2). Apakah ada pengaruh antara kualitas pelayanan, citra perusahaan, dan kepuasan pelanggan secara parsial terhadap loyalitas pelanggan pada (PDAM) kota Probolinggo? 3). Diantara ketiga variabel yaitu kualitas pelayanan, citra perusahaan, dan kepuasan pelanggan mana yang paling berpengaruh dominan terhadap loyalitas pelanggan pada (PDAM) kota Probolinggo.

Berdasarkan permasalahan yang sudah dirumuskan tersebut, maka tujuan penelitian ini adalah (1) Untuk mengetahui pengaruh antara kualitas pelayanan, citra perusahaan, dan kepuasan pelanggan secara simultan terhadap loyalitas pelanggan pada (PDAM) kota Probolinggo (2) Untuk mengetahui pengaruh antara kualitas pelayanan, citra perusahaan, dan kepuasan pelanggan secara sendiri sendiri terhadap loyalitas pelanggan pada (PDAM) kota Probolinggo (3) Untuk mengetahui pengaruh yang dominan antara variabel kualitas pelayanan, citra perusahaan, dan kepuasan pelanggan terhadap loyalitas pelanggan pada (PDAM) kota Probolinggo. 


\section{Tinjauan Pustaka}

\section{Pengertian Kualitas Pelayanan}

Setiap perusahaan tentunya akan terus menerus meningkatkan kualitas kinerjanya untuk tercapainya standar kualitas yang tinggi dalam mempertahankan pelanggannya. Karena bukan tidak mungkin seseorang yang hendak mendapatkan pelayanan mempunyai harapan tentang tingkatan pelayanan yang mereka inginkan.

Menurut Tjiptono (2012: 77) "Kualitas pelayanan mencerminkan perbandingan antara tingkat layanan yang disampaikan perusahaan dibandingkan ekspektasi pelanggan". Kualitas pelayanan diwujudkan melalui pemenuhan kebutuhan dan keinginan pelanggan serta ketepatan penyampaiannya dalam mengimbangi atau melampaui harapan pelanggan. Harapan pelanggan bisa berupa tiga standar. Pertama, will expectation; Kedua, should expectation, yaitu tingkat kinerja yang dianggap sudah sepantasnya diterima konsumen; Ketiga, ideal expectation, yaitu tingkat kinerja optimum atau terbaik yang diharapakan dapat diterima konsumen. Singkat kata, faktor utama yang mempengaruhi kualitas pelayanan ada dua yaitu persepsi pelanggan atas layanan yang nyata mereka terima (perceived service) dengan layanan yang sesungguhnya diharapkan atau diinginkan (expected service).

Menurut Tjiptono (2016: 123) "Sikap atau cara karyawan dalam melayani pelanggan secara memuaskan berperan besar dalam menciptakan keunggulan kualitas layanan (service excellece)". Keunggulan seperti ini dibentuk melalui pengintegrasian empat pilar yang saling berkaitan erat: kecepatan, ketepatan, keramahan, dan kenyamanan layanan. Keunggulan kualitas layanan tidak bisa terwujud apabila ada salah satu pilar yang lemah. Untuk mencapainya, setiap karyawan harus memiliki keterampilan khusus, diantaranya memahami layanan secara mendalam, berpenampilan rapi dan menarik, bersikap ramah dan bersahabat, menunjukkan komitmen dan responsivitas dalam melayani pelanggan, tidak tinggi hati karena merasa dibutuhkan, menguasai pekerjaan yang berkaitan langsung meupun tidak langsung dengan departemennya, mampu berkomunikasi secara efektif, bisa memahami dengan baik bahasa isyarat pelanggan, dan mampu 
menangani keluhan pelanggan secara profesional. Sekalipun upaya mewujudkan hal tersebut bukanlah pekerjaan mudah, namun apabila sebuah organisasi mampu melakukannya, maka manfaat yang didapatkan sangat besar, baik bagi perusahaan, pelanggan, maupun karyawan.

\section{Indikator Kualitas Pelayanan}

Menurut Parasuraman dalam Ratnasari (2016: 107) berdasarkan salah satu studi mengenai SEVQUAL yang melibatkan 800 pelanggan (yang terbagi dalam empat perusahaan) berusia 25 tahun keatas disimpulkan, terdapat 5 dimensi SEVQUAL, yaitu sebagai berikut.

a. Tangible atau bukti fisik.

b. Reliability atau keandalan.

c. Responsiveness atau ketanggapan.

d. Assurance atau jaminan dan kepastian. yaitu pengetahuan, kesopan-santunan.

e. Empathy atau empati, yaitu memberikan perhatian, tulus, dan bersifat individual atau pribadi kepada pelanggan dengan berupaya memahami keinginan pelanggan,

\section{Citra Perusahaan}

\section{Pengertian Citra Perusahaan}

Setiap perusahaan dalam melaksanakan kegiatan usahanya khususnya untuk kegiatan pemasaran memiliki suatu tujuan yaitu meningkatkan penjualan perusahaan. Salah satu caranya adalah dengan mempertahankan citra mereka dimata konsumen, terlebih dimata pelanggan yang meletakkan loyalitasnya pada perusahaan.

Menurut Siswanto dalam Ardianto (2016: 63) "Citra sebagai pancaran atau reproduksi jati diri atau bentuk orang perseorangan, benda atau organisasi”.

\section{Indikator Citra Perusahaan}

Menurut Shirley Harrison (dalam Julia, 2015: 5) mengemukakan bahwa informasi yang lengkap mengenai citra perusahaan meliputi empat elemen yaitu sebagai berikut: 
1) Kepribadian (personality). Reputasi (reputation). Hal yang telah dilakukan perusahaan dan diyakini publik sasaran maupun pihak lain.

2) Nilai (value).

3) Identitas Perusahaan (corporate identity).

\section{Kepuasan Pelanggan}

\section{Pengertian Kepuasan Pelanggan}

Dari seluruh proses kegiatan pemberian pelayanan jasa kepada pelanggan oleh sebuah perusahaan, pada akhirnya akan bermuara pada nilai yang akan diberikan oleh pelanggan mengenai kepuasan yang dirasakan.

Kepuasan adalah perasaan baik yang anda miliki ketika anda mencapai sesuatu atau ketika sesuatu yang anda inginkan terjadi, tindakan pemenuhan dan kebutuhan atau keinginan, dan cara yang dapat diterima untuk menangani keluhan, hutang, cedera, dll.

Menurut Kano dalam Tjiptono (2016: 224) “Kepuasan pelanggan merupakan fungsi non-linear dari service functionally yang terdiri dari atas tiga komponen, yaitu attractve component, proportional (one-dimensional) component, dan "mustbe" component”. Kategorisasi ini didasarkan pada kemampuan atribut produk atau jasa dalam memuaskan kebutuhan konsumen.

Dalam upaya peningkatan kepuasan konsumen Kotler dalam Ratnasari (2016: 118) menyarankan untuk melakukan hal sebagai berikut: memperkecil kesenjangankesenjangan yang terjadi antara pihak manajemen dan konsumen. Perusaahaan harus amemberikan ide-ide baru dan masukan yang berharga kepada perusahaan, sehingga memungkinkannya untuk beraksi secara cerdas dan sigap dalam mengatasi masalah-masalah yang timbul.

\section{Indikator Kepuasan Pelanggan}

Menurut Lupiyoadi dalam Ratnasari (2016: 117) ada empat faktor utama yang perlu diperhatikan dalam kaitannya dengan kepuasan pelanggan yaitu:

1) Kualitas Produk;

2) Kualitas Pelayanan;

3) Emosional; 
4) Harga;

\section{Loyalitas Pelanggan}

\section{Pengertian Loyalitas Pelanggan}

Loyalitas pelanggan memiliki peran penting dalam sebuah perusahaan, mempertahankan mereka artinya kinerja keuangan ditingkatkan untuk mempertahankan kelangsungan hidup perusahaan, hal ini menjadi alasan utama bagi sebuah perusahaan untuk menarik dan mempertahankan mereka. Usaha untuk memperoleh pelanggan yang loyal tidak bisa spontan, tetapi harus melalui beberapa tahapan, mulai dari mencari pelanggan potensial sampai memperoleh partner.

Menurut Hill dalam Hurriyati (2015: 132), loyalitas pelanggan dibagi menjadi enam tahapan yaitu Suspect, Prospect, Customer, Clients, Advocates, dan Partners. Tahapan-tahapan tersebut dijelaskan sebagai berikut:

1) Suspect

Meliputi semua orang yang diyakini akan membeli (membutuhkan) barang/jasa, tetapi belum memiliki informasi terkait tersebut.

2) Prospect

3) Clients

4) Advocates

Pada tahap ini, Clients secara aktif mendukung perusahaan dengan memberikan rekomendasi kepada orang lain agar mau membeli barang/jasa di perusahaan teersebut.

5) Partners

Pada tahap ini telah terjadi hubungan yang kuat dan saling menguntungkan antara perusahaan dengan pelanggan, pada tahap ini pelanggan berani menolak produk/jas adari perusahaan lain.

\section{Indikator Loyalitas Pelanggan}

Loyalitas pelanggan merupakan hal yang sangat diperlukan bagi perusahaan, hal ini dapat dilihat dari karakteristik yang dimilikinya, sebagai mana diungkapkan Griffin dalam Hurriyati (2015: 130), pelanggan yang loyal memiliki kriteria sebagai berikut: 
1) Melakukan pembelian secara terus menerus (Makes reguler repeat puchases)

2) Membeli diluar lini produk/jasa (Purchasen acros product and service lines)

3) Merekomendasikan produk ke orang lain (Refers other)

4) Menunjukkan kekebalan dari daya tarik produk sejenis dari kompetitor (Demonstrates an immunity ti the full of the competition).

\section{Metode Penelitian}

\section{Obyek penelitian}

Penelitian dilakukan di PDAM kota Probolinggo. Di Jln Hayam wuruk Probolinggo, tahun 2017.

\section{Teknik Pengumpulan Data}

Perolehan Data dalam penelitian meliputii : 1) Wawancara/interview. Wawancara diterapkan sebagai teknik pengumpulan berbagai data apabila ingin melakukan penelitian pendahuluan untuk menemukan masalah yang harus diteliti, dan bila peneliti ingin mengetahui berbagai hal dari responden yang lebih mendalam atau jumlah respondennya sedikit atau kecil. 2).Observasi. Observasi adalah merupakan cara yang terbaik untuk melihat tingkah laku didalam ruang waktu dan keadaan tertentu.Melalui observasi peneliti belajar mengenai perilaku dan makna atas perilaku tersebut. 3). Kuisioner (Angket). Kuisioner adalah teknik pengumpulan data dengan cara memberi seperangkat pertanyaan/ pernyataan tertulis kepada responden untuk dijawab. Teknik ini dilakukan untuk mengumpulkan data yang mau diteliti.

\section{Sumber Data}

Sumber data yang digunakan dalam penelitian ini berupa sumber data primer dan sekunder yang berupa data tentang perusahaan (gambaran umum, visi dan misi, struktur organisasi), hasil penyebaran kuesioner dan kutipan dari buku-buku terkait variabel-variabel yang digunakan.

\section{Metode Analisis Data}

Metode analisis dalam penelitian ini menggunakan pendekatan kuantitatif, karena hal ini berkenaan dengan perhitungan untuk menjawab rumusan permasalahan dan 
hipotesis dengan menggunakan analisis deskriptif, uji asumsi klasik, analisis linier berganda, koefisien determinasi dan uji hipotesis dengan menggunakan bantuan perangkat lunak Microsoft Excel dan SPSS (Statistical Package for Social Sciences).

\section{Hasil Dan Pembahasan}

\section{HASIL PENELITIAN}

Perolehan data-data dan informasi dilakukan dengan wawancara dan penyebaran kuesioner kepada responden secara langsung sbb:

\section{Hasil Analisis Data}

\section{Hasil Analisis Regresi Linear Berganda}

Tabel 1. Coefficients ${ }^{\mathrm{a}}$

\begin{tabular}{|c|c|c|c|c|c|}
\hline \multirow[t]{2}{*}{ Model } & \multicolumn{2}{|c|}{$\begin{array}{l}\text { Unstandardized } \\
\text { Coefficients }\end{array}$} & $\begin{array}{l}\text { Standardize } \\
\text { d } \\
\text { Coefficient } \\
\text { S }\end{array}$ & \multirow[t]{2}{*}{$\mathrm{T}$} & \multirow[t]{2}{*}{ Sig. } \\
\hline & B & $\begin{array}{l}\text { Std. } \\
\text { Error }\end{array}$ & Beta & & \\
\hline (Constant) & -.781 & 1.424 & & -.548 & .585 \\
\hline Kualitas_Pelayanan & .244 & .081 & .276 & 3.018 & .003 \\
\hline Citra_Perusahaan & .182 & .087 & .173 & 2.092 & .039 \\
\hline Kepuasan_Pelanggan & .396 & .086 & .440 & 4.607 & .000 \\
\hline
\end{tabular}

a. Dependent Variable: Loyalitas Pelanggan

Sumber : Data Primer diolah dengan SPSS, 2018

Dari tabel 1 diatas diperoleh persamaan regresi linier berganda sebagai berikut:

$$
\begin{aligned}
& Y=a+b_{1} X_{1}+b_{2} X_{2}+b_{3} X_{3} \\
& Y=-0,781+0,244 X_{1}+0,182 X_{2}+0,396 X_{3}
\end{aligned}
$$

Dimana : 
1. Diketahui nilai a sebesar $-0,781$ menyatakan jika tidak ada variabel Kualitas Pelayanan $\left(\mathrm{X}_{1}\right)$, variabel Citra Perusahaan $\left(\mathrm{X}_{2}\right)$, dan variabel Kepuasan Pelanggan maka akan diperoleh nilai Loyalitas Pelanggan (Y) sebesar 0,781 .

2. Koefisien Regresi $b_{1}$ (Kualitas Pelayanan) $=0,244$ yang menyatakan jika ada peningkatan Kualitas Pelayanan sebesar 1\% maka Loyalitas Pelanggan akan meningkat sebesar 24,4\%. Namun jika Kualitas Pelayanan menurun $1 \%$ maka Loyalitas Pelanggan juga turun sebesar 24,4\% dengan asumsi variabel bebas lainnya tetap $\left(\mathrm{X}_{2}\right.$ dan $\left.\mathrm{X}_{3}=0\right)$.

3. Koefisien Regresi $b_{2}($ Citra Perusahaan $)=0,182$ yang menyatakan jika ada jika ada peningkatan Citra Perusahaan sebesar 1\% maka Loyalitas Pelanggan akan meningkat sebesar 18,2\%. Namun jika Citra Perusahaan menurun 1\% maka Loyalitas Pelanggan juga turun sebesar 18,2\% dengan asumsi variabel bebas lainnya tetap $\left(\mathrm{X}_{1}\right.$ dan $\left.\mathrm{X}_{3}=0\right)$.

4. Koefisien Regresi $b_{3}$ (Kepuasan Pelanggan) $=0,396$ yang menyatakan jika ada jika ada peningkatan Kepuasan Pelanggan sebesar 1\% maka Loyalitas Pelanggan akan meningkat sebesar 39,6\%. Namun jika Kepuasan Pelanggan menurun 1\% maka Loyalitas Pelanggan juga turun sebesar 39,6\% dengan asumsi variabel bebas lainnya tetap $\left(X_{1}\right.$ dan $\left.X_{2}=0\right)$.

Berdasarkan regresi diatas, variabel Kepuasan Pelanggan (X3) merupakan variabel yang paling besar pengaruhnya terhadap variabel Loyalitas Pelanggan (Y) yaitu sebesar $36,9 \%$ tiap $1 \%$ peningkatan atau penurunan Kepuasan Pelanggan itu sendiri.

\section{Hasil Koefisien Determinasi}

Tabel 2. Model Summary

\begin{tabular}{|l|l|l|l|l|}
\hline Model & $R$ & R Square & $\begin{array}{l}\text { Adjusted R } \\
\text { Square }\end{array}$ & $\begin{array}{l}\text { Std. Error of } \\
\text { the Estimate }\end{array}$ \\
\hline 1 & $.785^{\mathrm{a}}$ & .616 & .604 & 1.115 \\
\hline
\end{tabular}


a. Predictors: (Constant), Kepuasan Pelanggan, Citra Perusahaan, Kualitas Pelayanan

b. Dependent Variable: Loyalitas Pelanggan

Sumber : Data Primer diolah dengan SPSS, 2018

Berdasarkan tabel 2 diatas dapat dilihat bahwa nilai koefisien determinasi $\left(\mathrm{R}^{2}\right)$ sebesar 0,616 hal ini berarti 61,6\% variabel dependen Loyalitas Pelanggan dipengaruhi oleh variabel independen yaitu X1, X2, X3. Sedangkan sisanya 38,4\% dipengaruhi oleh faktor lain.

\section{Pengujian Hipotesis}

\section{Uji F (Pengujian Signifikan Secara Simultan)}

Tabel 3. ANOVA ${ }^{\mathrm{a}}$

\begin{tabular}{|ll|l|l|l|l|l|}
\hline \multicolumn{2}{|l|}{ Model } & $\begin{array}{l}\text { Sum of } \\
\text { Squares }\end{array}$ & Df & $\begin{array}{l}\text { Mean } \\
\text { Square }\end{array}$ & F & Sig. \\
\hline $1 \quad \begin{array}{l}\text { Regressi } \\
\text { on } \\
\text { Residual } \\
\text { Total }\end{array}$ & 1189.853 & 3 & 63.284 & 50.886 & $.000^{\mathrm{b}}$ \\
& 308.000 & 98 & 95 & 1.244 & & \\
\hline
\end{tabular}

a. Dependent Variable: Loyalitas Pelanggan

b. Predictors: (Constant), Kepuasan Pelanggan, Citra Perusahaan, Kualitas Pelayanan

Sumber : Data Primer diolah dengan SPSS, 2018

Berdasarkan tabel 3 diatas, hasil pengujian menunjukkan nilai $F_{\text {hitung }}$ 50,886 lebih besar dari $F_{\text {tabel }} 3,09$ dengan nilai sig. $F=0,000<0,05$ berarti bahwa variabel bebas secara simultan (bersama-sama) berpengaruh nyata terhadap variabel terikat.

Berdasarkan hasil uji F, terbukti jika hipotesis kesatu dapat diterima yaitu "Diduga ada pengaruh yang signifikan antara Kualitas Pelayanan, Citra Perusahaan, dan Kepuasan Pelanggan secara simultan terhadap Loyalitas Pelanggan Pada (PDAM) Kota Probolinggo". 


\section{Uji T (Pengujian Signifikan Secara Parsial)}

Tabel 4. Coefficients ${ }^{\mathrm{a}}$

\begin{tabular}{|c|c|c|c|c|c|}
\hline \multirow[t]{2}{*}{ Model } & \multicolumn{2}{|c|}{$\begin{array}{l}\text { Unstandardized } \\
\text { Coefficients }\end{array}$} & \multirow{2}{*}{$\begin{array}{l}\text { Standardize } \\
\text { d } \\
\text { Coefficient } \\
\text { s } \\
\text { Beta }\end{array}$} & \multirow[t]{2}{*}{$\mathrm{t}$} & \multirow[t]{2}{*}{ Sig. } \\
\hline & B & $\begin{array}{l}\text { Std. } \\
\text { Error }\end{array}$ & & & \\
\hline 1 (Constant) & -.781 & 1.424 & & -.548 & .585 \\
\hline $\begin{array}{l}\text { Kualitas_Pelayana } \\
\mathrm{n}\end{array}$ & .244 & .081 & .276 & 3.018 & .003 \\
\hline Citra_Perusahaan & .182 & .087 & .173 & 2.092 & .039 \\
\hline $\begin{array}{l}\text { Kepuasan_Pelang } \\
\text { gan }\end{array}$ & .396 & .086 & .440 & 4.607 & .000 \\
\hline
\end{tabular}

a. Dependent Variable: Loyalitas Pelanggan

Sumber : Data Primer diolah dengan SPSS, 2018

Berdasarkan data tabel diatas diperoleh nilai $t_{\text {hitung variabel Kualitas Pelayanan }}$ $\left(\mathrm{X}_{1}\right)$ sebesar 3,018 lebih besar dari $\mathrm{t}_{\text {tabel }}$ yaitu 1,664, dengan nilai sig. $\mathrm{t}=0,003$, karena nilai sig. $\mathrm{t}<0,05$, maka terdapat pengaruh yang signifikan antara Kualitas Pelayanan terhadap Loyalitas Pelanggan. Kemudian diperoleh nilai $t_{\text {hitung }}$ untuk variabel Citra Perusahaan $\left(\mathrm{X}_{2}\right)$ sebesar 2,092 lebih besar dari $t_{\text {tabel }}$ yaitu 1,664, dengan nilai sig. $\mathrm{t}=0,039$, karena nilai sig. $\mathrm{t}<0,05$, maka terdapat pengaruh yang signifikan antara Citra Perusahaan terhadap Loyalitas Pelanggan. Dan untuk variabel Kepuasan Pelanggan diperoleh nilai $t_{\text {hitung }}$ sebesar 4,607 lebih besar dari tabel yaitu 1,664, dengan nilai sig. 0,000, karena nilai sig. $\mathrm{t}<0,05$, maka ada pengaruh yang nyata antara Kepuasan Pelanggan terhadap Loyalitas Pelanggan.

Dengan demikian terbukti jika hipotesis kedua dapat diterima yaitu "Diduga ada pengaruh nyata antara Kualitas Pelayanan, Citra Perusahaan, dan Kepuasan 
Pelanggan secara parsial Pada (PDAM) Kota Probolinggo".

\section{Uji Dominan}

Berdasarkan data pada Tabel 4, dapat diketahui bahwa variabel Kepuasan Pelanggan (X3) memiliki nilai t hitung lebih tinggi sehingga berpengaruh terhadap Loyalitas Pelanggan, hal ini ditunjukkan dari nilai $t_{\text {hitung }}$ variabel Kepuasan Pelanggan $\left(\mathrm{X}_{3}\right)=4,607$ dengan nilai sig. $\mathrm{t}=0,000$.

Dengan demikian terbukti jika hipotesis ketiga dapat diterima yaitu "Diduga Variabel Kepuasan Pelanggan berpengaruh secara dominan terhadap Loyalitas Pelanggan pada (PDAM) kota Probolinggo".

\section{Hasil Kerangka Berfikir}

Setelah dilakukan pengujian statistik baik secara simultan (bersama-sama) dengan menggunakan uji F maupun secara parsial (masing-masing) dengan menggunakan uji T, maka dapat diketahui hasil dari kerangka berfikir adalah sebagai berikut :

a. Pengaruh Kualitas Pelayanan terhadap Loyalitas Pelanggan

Hasil pengujian diperoleh thitung untuk variabel Kualitas Pelayanan lebih besar dari $t_{\text {tabel }}$ yaitu sebesar 3,018 $>1,664$ dengan nilai sig. $=0,003<0,05$. Sehingga terbukti Kualitas Pelayanan berpengaruh signifikan terhadap Loyalitas Pelanggan pada (PDAM) Kota Probolinggo.

b. Pengaruh Citra Perusahaan terhadap Loyalitas Pelanggan

Hasil pengujian diperoleh $t_{\text {hitung }}$ untuk variabel Kualitas Layanan lebih besar dari $\mathrm{t}_{\text {tabel }}$ yaitu sebesar 2,092 $>1,664$ dengan nilai sig. $=0,039<0,05$. Sehingga terbukti Citra Perusahaan berpengaruh signifikan terhadap Loyalitas Pelanggan pada (PDAM) Kota Probolinggo.

c. Pengaruh Kepuasan Pelanggan terhadap Loyalitas Pelanggan

Hasil pengujian diperoleh thitung untuk variabel Kualitas Layanan lebih besar dari tabel yaitu sebesar 4,607 > 1,664 dengan nilai sig. $=0,000<0,05$. Sehingga dari hasil analisis tersebut dapat disimpulkan bahwa terbukti Kepuasan Pelanggan berpengaruh signifikan terhadap Loyalitas Pelanggan pada (PDAM) Kota Probolinggo.

d. Pengaruh Dominan

Variabel bebas yang dominan berpengaruh terhadap variabel terikat dapat 
diketahui dari nilai thitung variabel Kepuasan Pelanggan $\left(\mathrm{X}_{3}\right)=4,607$ dengan nilai sig. $\mathrm{t}=0,000$ yang lebih besar dari nilai $\mathrm{t}_{\text {hitung variabel Kualitas Pelayanan }}$ $\left(\mathrm{X}_{1}\right)=3,019$ dengan nilai sig. $\mathrm{t}=0,003$ serta lebih besar dari variabel Citra Perusahaan $\left(\mathrm{X}_{2}\right)=2,092$ dengan nilai sig. $\mathrm{t}=0,039$.

Dengan demikian terbukti jika hipotesis ketiga dapat diterima yaitu "Diduga Variabel Kepuasan Pelanggan berpengaruh secara dominan terhadap Loyalitas Pelanggan pada (PDAM) Kota Probolinggo".

\section{Pengaruh Kualitas Pelayanan Terhadap Loyalitas Pelanggan pada (PDAM) kota Probolinggo}

Dari uji T nilai thitung variabel Kualitas Pelayanan $\left(\mathrm{X}_{1}\right)$ sebesar 3,018 lebih besar dari $\mathrm{t}_{\text {tabel }}$ yaitu 1,664, dengan nilai sig. $\mathrm{t}=0,003$, karena nilai sig. $\mathrm{t}<0,05$, maka ada pengaruh yang nyata antara Kualitas Pelayanan terhadap Loyalitas Pelanggan. Hasil penelitian ini mendukung penelitian terdahulu yang telah dilakukan oleh Desan Henriawan (2015) yang menyatakan bahwa Kualitas Pelayanan memiliki pengaruh nyata terhadap Loyalitas Pelanggan.

\section{Pengaruh Citra Perusahaan Terhadap Loyalitas Pelanggan pada (PDAM) kota Probolinggo}

Dari hasil uji $\mathrm{T}$ diperoleh nilai $t_{\text {hitung }}$ untuk variabel Citra Perusahaan $\left(\mathrm{X}_{2}\right)$ sebesar 2,092 lebih besar dari tabel yaitu 1,664, dengan nilai sig. $\mathrm{t}=0,039$, karena nilai sig. $\mathrm{t}<0,05$, maka terdapat pengaruh yang nyata antara Citra Perusahaan terhadap Loyalitas Pelanggan. Hasil penelitian ini mendukung penelitian terdahulu yang telah dilakukan oleh Erwina Safitri (2016) yang menyatakan bahwa Citra Perusahaan Berpengaruh nyata terhadap Loyalitas Pelanggan. Dari uji T didapat t hitung sebesar 4,607 lebih besar dari tabel yaitu 1,664, dengan nilai sig.0,000. Karena nilai sig $\mathrm{t}<0,05$, maka ada pengaruh nyata.

\section{Pengaruh Kepuasan Pelanggan Terhadap Loyalitas Pelanggan (PDAM) kota Probolinggo}

Dari hasil uji T diperoleh nilai $t_{\text {hitung }}$ sebesar 4,607 lebih besar dari $t_{\text {tabel }}$ yaitu 1,664, dengan nilai sig. 0,000, karena nilai sig. $\mathrm{t}<0,05$, maka terdapat pengaruh yang nyata antara Kepuasan Pelanggan terhadap Loyalitas Pelanggan. Hasil penelitian ini mendukung penelitian terdahulu yang telah dilakukan oleh Abdul Basith (2014) 
yang menyatakan bahwa Kepuasan Pelanggan Berpengaruh nyata terhadap Loyalitas Pelanggan.

\section{Pengaruh Kualitas Pelayanan, Citra Perusahaan, dan Kepuasan Pelanggan Secara Simultan Terhadap Loyalitas Pelanggan pada (PDAM) kota Probolinggo}

Dari hasil uji $\mathrm{F}$ menunjukkan nilai $\mathrm{F}_{\text {hitung }}$ 50,886 lebih besar dari $\mathrm{F}_{\text {tabel }}$ 3,09 dengan nilai sig. $F=0,000<0,05$ berarti bahwa variabel bebas (Kualitas Pelayanan, Citra Perusahaan, dan Kepuasan Pelanggan) secara simultan (bersama-sama) berpengaruh signifikan terhadap variabel terikat (Loyalitas Pelanggan). Hasil penelitian ini mendukung penelitian terdahulu yang telah dilakukan oleh Deffriansah Pratama (2014) yang menyatakan bahwa Kualitas Pelayanan, Citra Perusahaan, dan Kepuasan Pelanggan Secara Simultan (bersama-sama) Berpengaruh signifikan terhadap Loyalitas Pelanggan dan variabel Kepuasan Pelanggan mempunyai pengaruh dominan dibandingkan variabel Citra Perusahaan dan Kualitas Pelayanan dengan nilai $t_{\text {htung }}$ sebesar 4,607.

\section{Kesimpulan}

Secara simultan Kualitas Pelayanan, Citra Perusahaan, dan Kepuasan Pelanggan berpengaruh terhadap Loyalitas Pelanggan pada (PDAM) kota Probolinggo. Uji parsial (Uji t) menunjukkan bahwa secara parsial Kualitas Pelayanan, Citra Perusahaan, dan Kepuasan Pelanggan berpengaruh signifikan terhadap Loyalitas Pelanggan, hal ini ditunjukkan oleh nilai $t_{\text {hitung }}$ yang lebih besar dari pada $t_{\text {tabel. }}$. Dari hasil uji t dapat dilihat bahwa variabel Kepuasan Pelanggan berpengaruh dominan terhadap Loyalitas Pelanggan pada (PDAM) kota Probolinggo.

\section{DAFTAR PUSTAKA}

Ardianto Elvirano. 2016. Handbook Of Public Relations: Pengantar Komprehensif. Bandung: CV Simbiosa Rekatama Media.

Arikunto, Suharsimi. 2013. Prosedur Penelitian Suatu Pendekatan Praktik. PT Rineka Cipta.

Haris, Abdul. 2016. Manajemen Pemasaran: Tinjauan Teoritis dan Praktik. Malang: Surya Pena Gemilang 
Henriawan, Desan. 2015. Pengaruh Kualitas Pelayanan dan Kepuasan Pelanggan Terhadap Loyalitas Pelanggan (Studi Kasus Pada Toko Cabang Mufin Wilayah Bandung Timur). Copetition, Volume VI, Nomor 2, 71-82.

Hurriyati Ratih. 2015. Bauran Pemasaran dan Loyalitas Konsumen. Bandung: CV Alfabeta.

Kotler Phillip, dan Keller Kevin Lane. 2009. Manajemen Pemasaran Jilid 1 Edisi 13. Jakarta: Erlangga.

Normasari, Selvy dkk. 2013. Pengaruh Kualitas Pelayanan Terhadap Kepuasan Pelanggan, Citra Perusahaan, dan Loyalitas Pelanggan. Jurnal Administrasi Bisnis (JAB), Volume VI, Nomor 2.

Priyatno, Duwi. 2016. Mandiri Belajar SPSS (Statistical Product and Service Solution). Yogyakarta: Media Kom.

Ratnasari, Ririn Tri, dan Aksa Mashuti H. 2016. Manajemen Pemasaran Jasa. Surabaya: Ghalia Indonesia.

Rajagukguk, Julia Resti dan Kasmiruddin. 2015. Pengaruh Kualitas Pelayanan dan Citra Perusahaan Terhadap Kepuasan Pelangggan Industri Jasa Bengkel (Studi Kasus PT. Mewah Kencana Motor Pekanbaru). JOM FISIP, Volume 2, Nomor 2.

Sugiyono. 2017. Metode Penelitian Kuantitatif, Kualitatif dan R\&D. Bandung: Alfabeta.

Sunyoto, Danang. 2011. Metode Penelitian Ekonomi Alat Statistik \& Analisis Output Komputer. CAPS.

Tjiptono, Fandy, dan Candra Gregorius. 2012. Pemasaran Strategik. Yogyakarta: Andi.

Tjiptono, Fandy, dan Candra Gregorius. 2016. Service, Quality, dan Satisfaction. Yogyakarta: Andi. 